\title{
TEXTURE ANALYSIS OF A ZINC LAYER ON A STEEL SUBSTRATE USING NEUTRON DIFFRACTION
}

\author{
H.-G. BROKMEIER \\ Department of Physical Metallurgy, TU Clausthal and GKSS-Research Center \\ Geesthacht GmbH, FRG
}

(Received 26 June 1992)

\begin{abstract}
This paper describes the application of neutron diffraction to investigate the texture of a zinc layer $8 \mu \mathrm{m}$ in thickness. In a nondestructive way both the texture of the zinc layer as well as the texture of the steel substrate were studied. Therefore, pole figures of iron $((110),(200)$ and $(211))$ and of zinc

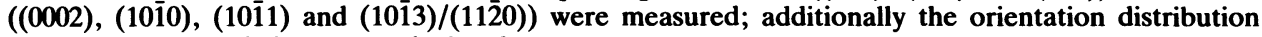
function of iron and zinc were calculated.
\end{abstract}

KEY WORDS Iron substrate, zinc coating, composite sample, neutron diffraction, ODF analysis.

\section{INTRODUCTION}

The texture is one of the parameters to describe anisotropic physical and mechanical properties of polycrystalline materials. In the case of coatings, the textures of both the substrate as well as the coating themselves are essential for an optimization of the preparation technique, for a sufficient adhesion and for optimization of the coating thickness. Therefore, both textures have to be measured.

In general, neutron diffraction texture measurements are carried out to determine the bulk texture of relatively large sample volumes, e.g. spheres, cylinders and cubes of 1-2 cm in diameter (Kleinstück et al. 1976; Welch, 1986; Bunge, 1990; Brokmeier, 1991). Thus, texture analysis of surface layers and thin films are normally performed by an X-ray technique. In the case of surface layers, the standard technique by Schulz (Bragg-Brentano geometry in reflection mode (1949)) is restricted. This reflection technique covers the surface as well as the substrate; subsequently difficulties in overlappings and difficulties in the amount of diffracting material are obtained. Hence, the low incident-angle diffraction technique (Segmüller and Murakami, 1985; Heizmann et al., 1989) is often preferred to increase the diffracting volume. Nevertheless, such an X-ray technique requires a surface etching to measure the substrate. On the other hand, it is well known that neutron diffraction allows the texture determination of minor components in a multi-phase system (Brokmeier and Bunge, 1988). Hence, the bulk technique by neutron diffraction offers the possibility to measure the texture of both components, the substrate and the surface layer, in a nondestructive way. 


\section{EXPERIMENT}

A steel sheet $0.7 \mathrm{~mm}$ thick was covered electrolytically by a zinc layer of $8-10 \mu \mathrm{m}$ thickness. Thereafter, sections of $12 \times 12 \mathrm{~mm}$ were prepared with the same sample orientation in order to produce a composite specimen. Finally, a cubic "neutron sample" of $12 \times 12 \times 12 \mathrm{~mm}$ with a total sample volume of $1728 \mathrm{~mm}^{3}$ results, which is shown in Figure 1. The composite sample contains approximately $1 \mathrm{Vol}$.\% $\mathrm{Zn}$. Depending on the high transmission of thermal neutrons (Bacon 1975) and on the large cross section of the neutron beam (Brokmeier et al., 1987) the spherical sample method after Tobisch and Bunge (1972) was used and the whole sample volume participates in the diffraction experiment. A vanadium-pin was used as a sample holder in order to restrict Bragg-reflections to those from the sample. This is due to the fact that vanadium has extremely low coherent scattering length (Bacon, 1975).

The neutron diffraction measurements were carried out using the TEX-2 texture diffractometer of GKSS-Research Center at Geesthacht (FRG). A primary collimation of $50 \mathrm{~min}$. and a $\mathrm{Cu}(111)$ monochromator lead to a neutron flux of $1.5 \times 10^{5} \mathrm{n} \mathrm{cm}^{-2} \mathrm{sec}^{-1}$ at the sample position, yielding neutrons with wavelengths of $1.388 \AA$.

Both, theoretically calculated and measured diffraction pattern were used to choose the pole figures which can be used for the texture analysis. Table 1 gives the relative intensities for $\mathrm{Fe}$ and $\mathrm{Zn}$ calculated with the LAZY PULVERIX programm (Yvon et al., 1977). Figure 2 shows a part of the diffraction pattern between $28.0^{\circ}-37.4^{\circ}$ in $2 \theta$. The two $\mathrm{Zn}$ reflections $(0002)$ and $10 \overline{10}$ ) respectively can be determined very well, while the (1011) of Zn shows a partial overlap with

Figure 1 Composite sample of sheet sections. 
Table 1 Relative intensities $I / I_{100}$ for $\mathrm{Fe}$ and $\mathrm{Zn}$ (calculated for $1.338 \AA$ neutrons)

\begin{tabular}{rrrr}
\hline $\boldsymbol{h} \boldsymbol{k l}$ & $\boldsymbol{F} \boldsymbol{c}$ & $\boldsymbol{h} \boldsymbol{k} \boldsymbol{l}$ & \multicolumn{1}{c}{$\mathrm{Zn}$} \\
\hline 110 & 100 & 0002 & 46 \\
200 & 27 & $10 \overline{1} 0$ & 20 \\
211 & 77 & $10 \overline{1} 1$ & 100 \\
222 & 31 & $10 \overline{1} 2$ & 34 \\
& & $10 \overline{1} 3$ & 67 \\
& & $11 \overline{2} 0$ & 44 \\
& & 0004 & 13 \\
\hline
\end{tabular}

$\mathrm{Fe}(110)$. Theoretically, overlapping reflections can be used in quantitative texture analysis (Bunge, 1969; Dahms et al., 1988), but in the case of the extremely dominating $\mathrm{Fe}$ against the minority phase of $\mathrm{Zn}$ the peak separations will be problematic.

In the case of Fe the three reflections (110), (200), (211) were measured, while in the case of $\mathrm{Zn}$ the reflections (0002), (1010), (1011), (1013), (1120) were measured. TEX-2 was equipped with a ${ }^{3} \mathrm{He}$-single detector. Hence, the measurements of the different pole figures were performed one after each other (Brokmeier 1989). A standard equal angular scanning routine was used with $\Delta \chi=5^{\circ}$ and $\Delta \varphi=5^{\circ}$ such that 1368 pole figure points were obtained. The characteristic data of the measured pole figures are shown in Table 2. BG are values of the background measurements while I represents intensity values of the different Bragg-reflections. The time is given for one pole figure point.

\section{RESULTS AND DISCUSSION}

The data evaluation was carried out using the GKSS texture software described in detail by Dahms and Bunge $(1988,1989)$. In Figure 3, the measured as well the

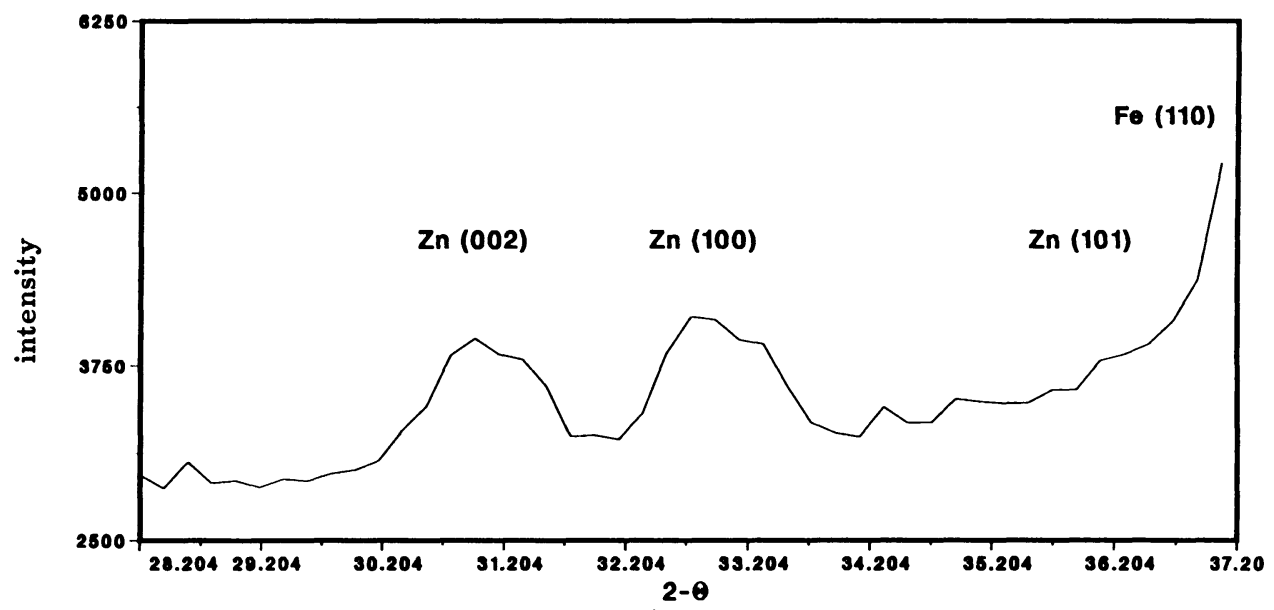

Figure 2 Part of the diffraction pattern including $3 \mathrm{Zn}$ reflections. 
Table 2 Data of the texture measurement

\begin{tabular}{|c|c|c|c|c|c|c|c|}
\hline Phase & $h k l$ & Points & Time & $I_{\max }$ & $I_{\min }$ & $B G_{\max }$ & $B G_{\min }$ \\
\hline $\mathrm{Zn}$ & $\begin{array}{r}0002 \\
10 \overline{1} 0 \\
10 \overline{1} 1 \\
10 \overline{1} 3 / 11 \overline{2} 0\end{array}$ & $\begin{array}{l}1368 \\
1368 \\
1368 \\
1368\end{array}$ & $\begin{array}{r}80 \mathrm{sec} . \\
120 \mathrm{sec} . \\
85 \mathrm{sec} . \\
85 \mathrm{sec} .\end{array}$ & $\begin{array}{r}966 \\
1210 \\
2381 \\
799\end{array}$ & $\begin{array}{l}494 \\
750 \\
495 \\
527\end{array}$ & $\begin{array}{l}557 \\
809 \\
551 \\
552\end{array}$ & $\begin{array}{l}506 \\
768 \\
475 \\
502\end{array}$ \\
\hline $\mathrm{Fe}$ & $\begin{array}{l}110 \\
200 \\
211\end{array}$ & $\begin{array}{l}1368 \\
1368 \\
1368\end{array}$ & $\begin{array}{l}6 \text { sec. } \\
8 \text { sec. } \\
10 \text { sec. }\end{array}$ & $\begin{array}{l}4848 \\
1606 \\
2687\end{array}$ & $\begin{array}{r}105 \\
55 \\
296\end{array}$ & $\begin{array}{r}50 \\
75 \\
107\end{array}$ & $\begin{array}{l}36 \\
44 \\
61\end{array}$ \\
\hline
\end{tabular}

Fe (110) measured

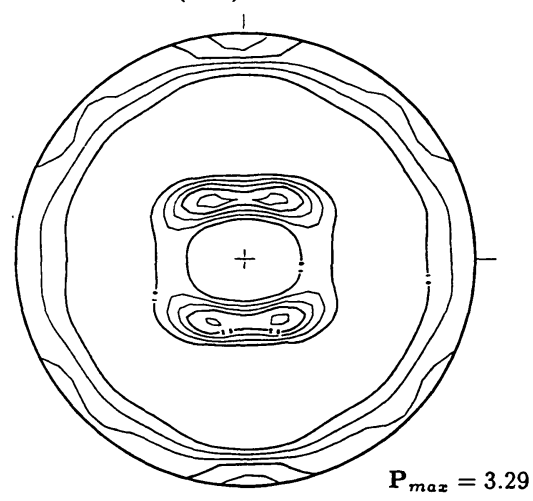

Fe (110) recalculated

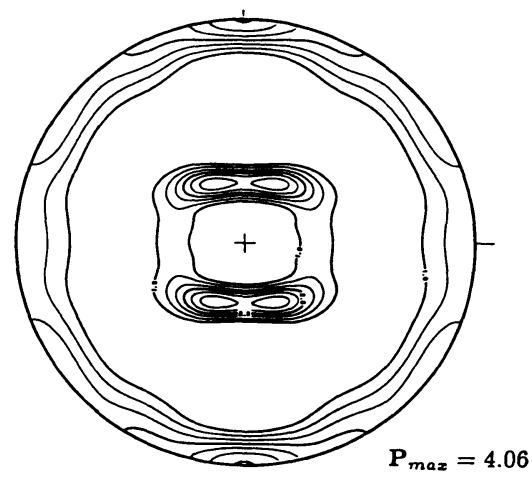

Figure 3 Measured and recalculated pole figures of $\mathrm{Fe}(110)$.
Zn (0002) measured

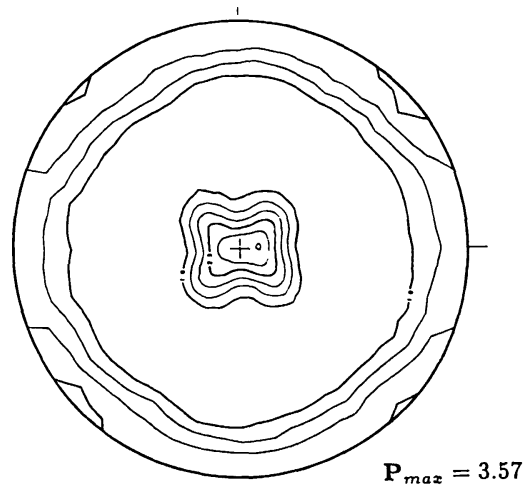

Zn (0002) recalculated

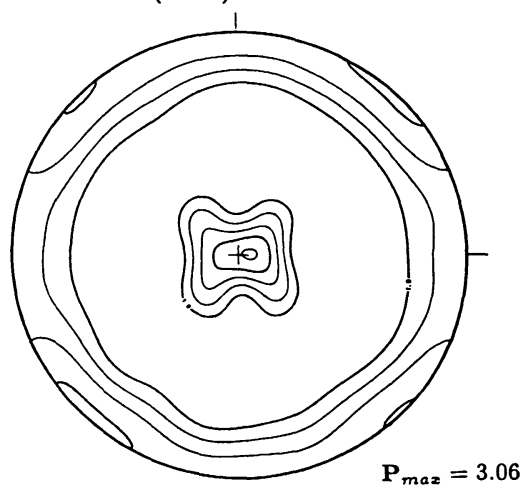

Figure 4 Measured and recalculated pole figures of $\mathrm{Zn} \mathrm{(0002).}$ 
recalculated (110) pole figure of the Fe-substrate is shown. The orientation distribution function (ODF) was calculated using the series expansion method, see Bunge (1982), up to $L_{\max }=23$. A comparison of the measured and the recalculated pole figure shows high agreement. That means the zinc layers embedded in the composite sample have no influence on the texture measurement of the substrate, and a quantitative texture analysis of such a multi-layer

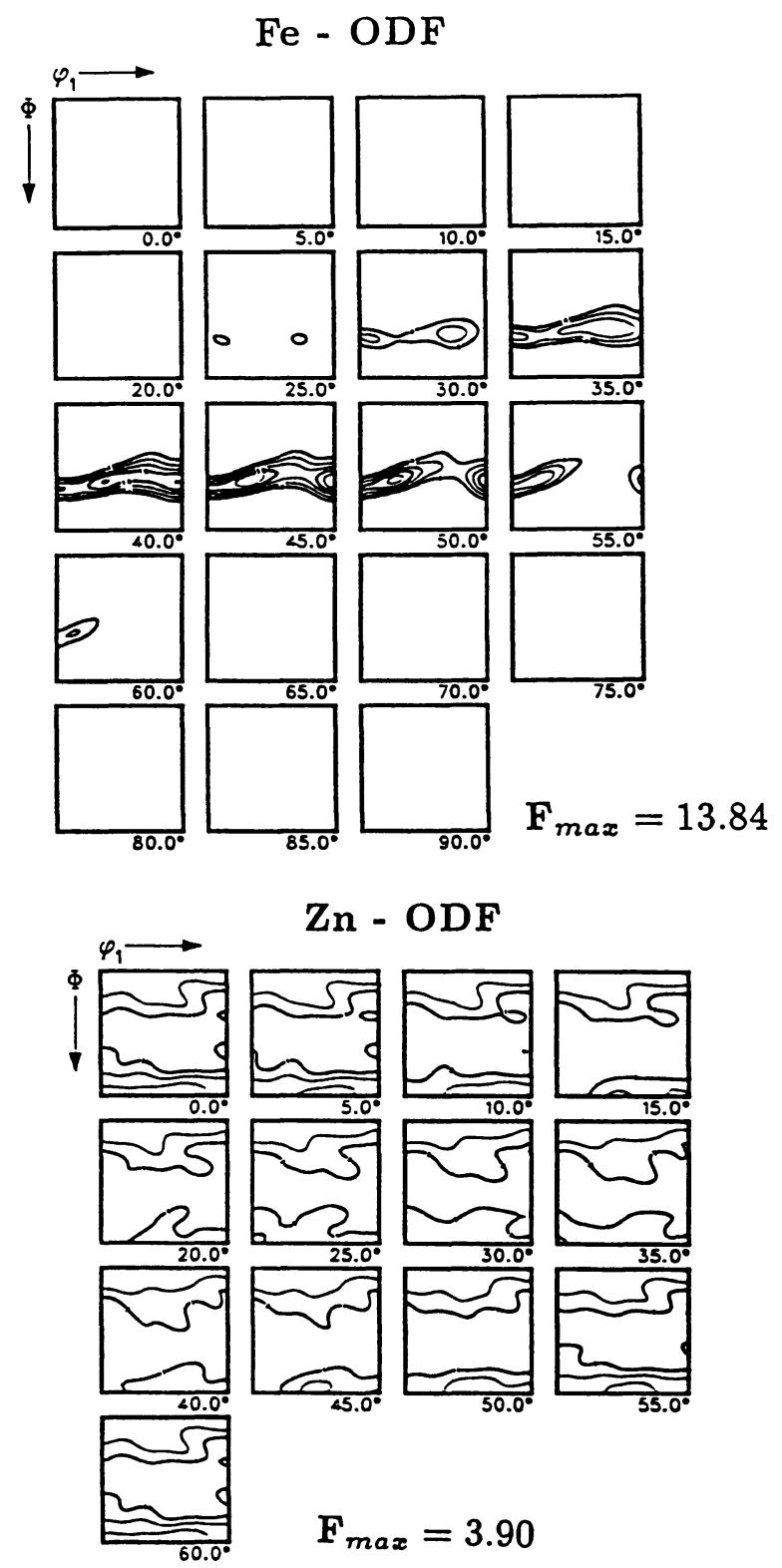

Figure 5 Orientation distribution function of $\mathrm{Fe}$ and $\mathrm{Zn}$. 
sample can be performed with a high accuracy. This depends on the fact, that in neutron diffraction anisotropic absorption (Bunge, 1986) can be neglected.

In the case of the $\mathrm{Zn}$ texture the two separate reflections (0002) and (1010) and the two overlapping reflections (1013) and (1120) were used for ODF-calculation. Best results were obtained using a series expansion degree of $L_{\max }=17$ and a random texture component (see Dahms, 1992) $\mathrm{RTC}=0.50$. For example the (0002) pole figure of the $\mathrm{Zn}$-layer measured and recalculated is given in Figure 4.

The orientation distributions of both phases, the Fe-substrate and Zn-layer, are shown in Figure 5 using one of the standard drawings for ODF-representation (Wenk et al., 1988). A comparison of these results and prior investigations by Vlad et al. (1988) show good agreement. The Fe texture mainly consists of a $\langle 111\rangle$ fibre which was illustrated by the recalculated (111) pole figure and the inverse pole figure in normal direction (Figure 6a and 6b). The texture of the Zn-layer can be described by two different texture components. A first texture component is a $\langle 11 \overline{2} 0\rangle$ fibre. This texture component represents the first formation of $\mathrm{Zn}$ on Fe which was described by Vlad et al. (1988) as an alloy layer. The second texture component was the desirable (0001) fibre texture.

It can be concluded that neutron diffraction allows the quantitative texture analysis of a thin $\mathrm{Zn}$-layer on a Fe-substrate in a non-destructive way. A

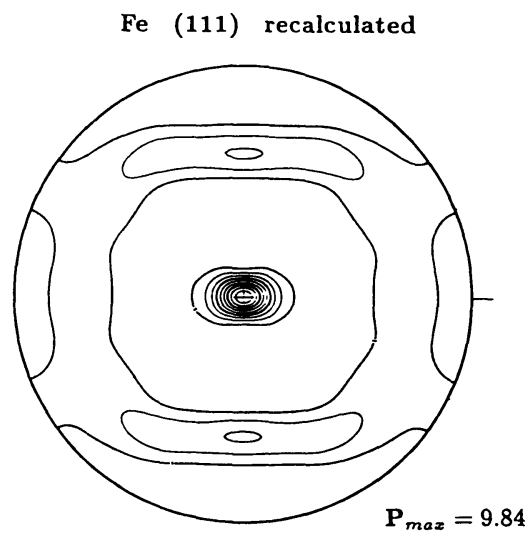

(a)

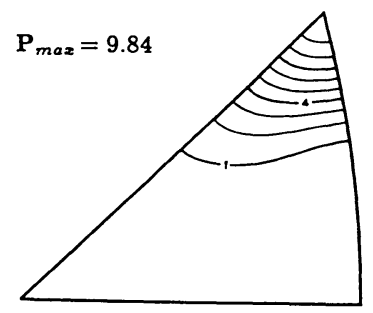

Fe - inverse pole figure

(b)
Figure 6 (a) Recalculated (111) pole figure of the Fe-substrate. (b) Inverse pole figure in normal direction of the Fe-substrate. 
minimum thickness of a thin film which can be studied by neutron diffcation cannot be given. This thickness depends strongly on the texture and on the reflectivity of the layer forming material. Both texture and reflectivity influence the peak/background ratio. Finally it can be pointed out that the sharper the texture, the lower the minimum thickness.

\section{ACKNOWLEDGEMENTS}

The author would like to thank Dr. H. Klein for the test sample. This work has been funded by the German Federal Minister for Research and Technology (BMFT) under the contract number 03BU2CLA9.

\section{References}

Bacon, G. E. (1975). Neutron Diffraction. Clarendon Press, Oxford.

Brokmeier, H.-G. (1989). Neutron Diffraction Texture Analysis of Multi-Phase Systems. Textures Microstruc. 10, 325-346.

Brokmeier, H.-G. (1991). Neutron Diffraction Texture Analysis. In Advances and Application of Quantitative Texture Analysis edited by H. J. Bunge, C. Esling, pp 73-86. DGM Informationsgesellschaft, Oberursel, Germany.

Brokmeier, H.-G. and Bunge, H. J. (1988). Neutron Diffraction Texture Analysis of $1 \mathrm{Vol} . \% \mathrm{Cu}$ in Aluminium. Textures Microstruc. 10, 1-8.

Brokmeier, H.-G., Bunge, H. J., Brehler, B., Wagner, R. and Wille, P. (1987). Texturmessungen am FRG-1. GKSS-Report 87/E/42.

Bunge, H. J. (1969) Mathematische Methoden der Texturanalys. Akademie Verlag, Berlin, Germany.

Bunge, H. J. (1986). Anisotropic Absorption in Multiphase Texture Analysis. In Experimental Techniques of Texture Analysis edited by H. J. Bunge, pp 395-402. DGM-Informationsgesellschaft, Oberursel, Germany.

Bunge, H. J. (1989). Advantages of Neutron Diffraction in Texture Analysis. Textures Microstruc. 10, 265-308.

Dahms, M. (1992). Introduction of the Phone-Concept into Pole Figure Inversion using the Iterative Series Expansion Method. Textures Microstruc. 19, 169-174.

Dahms, M. and Bunge, H. J. (1988). A Positivity Method for the Determination of Complete Orientation Distribution functions. Textures Microstruc. 10, 21-35.

Dahms, M. and Bunge, H. J. (1989). The Iterative Series-Expansion Method for Quantitative Texture Analysis. I. General Outline. J. Appl. Cryst. 22, 439-447.

Dahms, M., Brokmeier, H.-G., Seute, H., Bunge, H. J. (1987). Quantitative Texture Analysis in Multiphase Materials with Overlapping Bragg-Reflections. In Mechanical and Physical Behaviour of Metallic and Ceramic Composites edited by S. I. Anderson, H. Lilholt, O. B. Petersen, pp. 327-332, Risø National Laboratory, Roskilde, DK.

Heizmann, J. L., Vadon, A., Schlatter, D., Bessieres, J. (1989). Texture Analysis of Thin Films and Surface Layers by Low Incidence Angle X-Ray Diffraction. Advances in X-ray Analysis 32, 285-292.

Kleinstück, K., Tobisch, J., Betzl, M., Mücklich, A., Schläfer, D., Schläfer, U. (1976). Texturuntersuchungen von Metallen mittels Neutronenbeugung. Krist. Tech. 11, 409-429.

Schulz, L. G. (1949). Direct Method of Determining Preferred Orientations of a Flat Reflection Sample using a Geiger Counter X-ray Spectrometer. J. Appl. Phys. 20, 1030-1033.

Segmüller, A. and Murakami, M. (1985). Characterisation of Thin Films by X-ray Diffraction. In Thin Films from Free Atoms and Particles edited by J. Klabunde, pp 325-351. Academic Press, New York, USA.

Tobisch, J. and Bunge, H. J. (1972). The Spherical Sample Method in Neutron Diffraction Texture Determination. Texture 1, 125-127.

Vlad, C. M., Dahms, M. and Bunge, H. J. (1988). ODF Analysis of Galfan- and Galvanized Hot Dipped Coatings of Low Carbon Steel Sheets. In Proceedings of ICOTOM 8 edited by J. S. Kallend, G. Gottstein, pp. 855-860, TMS-AIME, Warrendale, Pennsylvania, USA. 
Welch, P. I. (1986). Neutron Diffraction Texture Analysis. In Experimental Techniques of Texture Analysis edited by H. J. Bunge, pp 183-207. DGM-Informationsgesellschaft Oberursel, Germany. Wenk, H. R., Bunge, H. J., Kallend, J. S., Lücke, K., Matthies, S., Pospiech, J. and van Houtte, P. (1988). Orientation Distributions: Representation and determination. In Proceedings of ICOTOM 9 edited by J. S. Kallend, G. Gottstein, pp 17-30, TMS-AIME, Warrendale, Pennsylvania, USA.

Yvon, K., Jeitschko, W. and Parthe, E. (1977). LAZY PULVERIX, a computer program for calculating X-ray and neutron diffraction powder patterns, J. Appl. Cryst. 10, 73-74. 